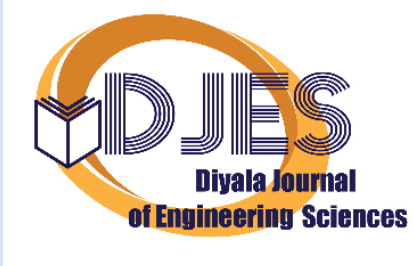

\title{
Applying Analytical Network Process to the Selection of Financing Method for Abandoned Construction Projects in Iraq
}

\author{
Huda Y. Khudhaire *, Hafeth I. Naji \\ Department of Civil Engineering, College of Engineering, University of Diyala, 32001 Diyala, Iraq
}

ARTICLE INFO

\section{Article history:}

Received 11 March 2021

Accepted 30 May 2021

Keywords:

Abandoned construction projects; PublicPrivate Partnership (PPP); Analytical

Network Process (ANP)

\begin{abstract}
Construction projects are of a special nature affected by many factors, which makes them exposed to multiple risks that may lead to the abandonment of projects. Recently, the Iraqi construction sector is facing a number of problems. Abandoned construction projects are one of the most common and dangerous problems in the construction industry in Iraq, with their negative effects on stakeholders, the economy, and the environment due to the lack of sufficient financial and administrative capabilities to complete construction projects, which is reflected in exceeding the time limit for the completion of projects. The aim of this research is to use the analytic network process (ANP) technique to choose the best form of Public-Private Partnership (PPP) contracts to fund abandoned projects in Iraq. using a questionnaire survey to determine the most criteria and alternatives for selecting appropriate financing for the abandoned project. The results shown final weight of the Build-Own-Operate (BOO) contract from ANP is 0.533, which is the best form of PPP contract among the alternatives proposed to fund the project.
\end{abstract}

\section{Introduction}

Abandoned construction projects are challenging to sustainable development for the construction industry; in many countries, many sectors of the construction industry have faced problems with abandoned construction projects due to economic, political, and legal conditions [1]. When construction works on a site have been suspended consistently for a period of 6 months or more, during the project completion term, or after the scheduled completion date, the project is considered abandoned; has a negative impact on the environment and society. [2]. Insufficient selection of the main contractor or subcontractor generates difficulties during construction. In addition, government policies, insufficient job requirements, poor quality control, and various climatic conditions lead to the abandonment of the project [3]. In recent years, the Iraqi construction sector faced many problems causes to abandoned projects, includes financing corruption, assigning work to companies with no experience in the field, incompetent contractors, administrative corruption, corruption of certain political parties, unexpected poor economic conditions, financial difficulties faced by the owner, and lack of legal responsibility [4]. Abandoned building projects negatively affect the real property value also reduces the aesthetics of neighborhoods, and increasing effects of environmental pollution [5]. Abandoned projects also adversely affect the health and safety of communities [6].

The performance of the construction industry is influenced by the national economies. The financial crisis has a major cause of abandoned many construction projects

* Corresponding author.

E-mail address: hudaeng3@gmail.com

DOI: $10.24237 /$ djes.2021.14206 
[7]. Public-Private Partnership (PPP) adopted in developing countries to overcome the lack of financial resources in governments [8]. Iraq, as a developing nation, faced a serious funding shortage as a result of the financial crisis. government agencies allowed private sector participation in financing projects abandoned as a result of the financial crisis [9]. It is obvious that the role of government, in this case, is of considerable significance since (1) such projects require a large budget, long lead time, and adequate risk tolerance, (2) These projects involve high social and economic costs that cannot be compensated with the user's money, (3) The strategic role of control. For this purpose, the use of private financing partnerships is a suitable alternative [10].

Type of PPP contracts is categorized according to the principles, patterns, and parameters adopted in the classification, such as the pattern of organization, decision-making, the form of the sector, nature of the activity, and nature of the contract; includes Build-OperateTransfer (BOT), Build-Own-Operate-Transfer (BOOT), Design-Build-Finance-Operate (DBFO), and Build-Own-Operate (BOO) Contracts [11]. PPP benefits include reducing public sector budget deficits, improving society's living conditions, providing highquality public goods and services, and reducing project time. However, the best PPP model will often be determined by a number of variables, including the project's goals, funding criteria, and business realities [12].

As a result, multicriteria decision-making (MCDM) methods can be applied to solve a wide range of decision-making situations. Analytical Network Process (ANP) is a multicriteria decision-making technique that allows a decision-maker to rank a collection of discrete alternatives. When there are several alternatives and criteria to consider, this approach is used [13]. ANP as mathematical theories allowed to dealing similarity within depending on feedbacks which make possible to jointed sensible and no intangible factors with use ratios scales [14]. The ANP is an extension of the analytical hierarchy process; ANP interdependence through the properties of the decision and allows more systematical tests.
Networks include cluster (component, criteria, node) also element (sub-criteria) in the cluster [15].

This study aims to select the best PPP model as an alternative method of government funding projects from the various strategies and tools provided by the Analytical Network Process (ANP) methodology.

\section{Literature review}

Many studies focused on the application of PPP in various aspects of the construction industry. Anopchenko et al. [16] selecting a PPP system for the management of sustainable development projects was analyzed using multicriteria decision-making (MCDM) for Modeling PPP in the innovative economy. The results of this study illustrate BOOT (0.53) concession model proved to be the most long-term option. It is required for the state to control and subsidize the private partner's operations during the design and construction stages in order for it to be implemented. Rezouki and Hassan [17] investigated the barriers to the application of PPP in infrastructure growth. The findings revealed that the poor legal framework, insufficient public administration procedures, delays in land acquisition, and a lack of sovereign guarantee are the most significant barriers to the adoption of (PPP) in infrastructure. Cheng et al. [18] investigated the viability of PPP as a sustainable development factor. Al-Shadeedi et al. [19] studied the key reasons for using PPP contracts in the health sector, can be solved by working with the private sector through a variety of partnership arrangements. Motlag \& Ghasemlounia, [20] encourage decision-makers to use PPP principles to improve service quality and innovation through the use of private sector knowledge and performance incentives.

\section{Research methodology}

The authors will use the key tools used for information collection are interviews, questionnaires, to identify the best strategies for improving the financing performance of the construction projects, using the analytical network process method, the framework for 
research is developed as shown in Figure (1). The methodology is organized as follows:

1. Theoretical study: Review of literature and studies in the area of public-private partnerships, the abandoned project area, and the field of ANP technology.

2. Practical study: The Practical study includes the gathering of data and information on the research topic as follows:

3. A case study is chosen, and data is gathered from engineering professionals.

a) Identify key criteria for the selection of the type of PPP in abandoned projects based on the literature and expert opinions as shown in Table 1.

b) The data was gathered by a field survey by a special questionnaire was prepared for this purpose and distributed to professionals working in the Iraqi construction sector, both public and private, where 45 questionnaires were distributed and the total return was 40 with an $88 \%$ response rate. The questionnaire is distributed using the interview process in order to assess the importance and priorities of the criteria and alternatives.

c) The Super Decisions software (v.3.2) used based on analytical network process (ANP) for builds the simplest decision model that has a goal, criteria, and alternatives make judgments (paired comparisons), and compute the results to find the best alternative, as shown in the figure (2).

d) making pairwise comparisons of the decision elements

e) estimating the weights of the decision elements and check consistency ratio (CR).

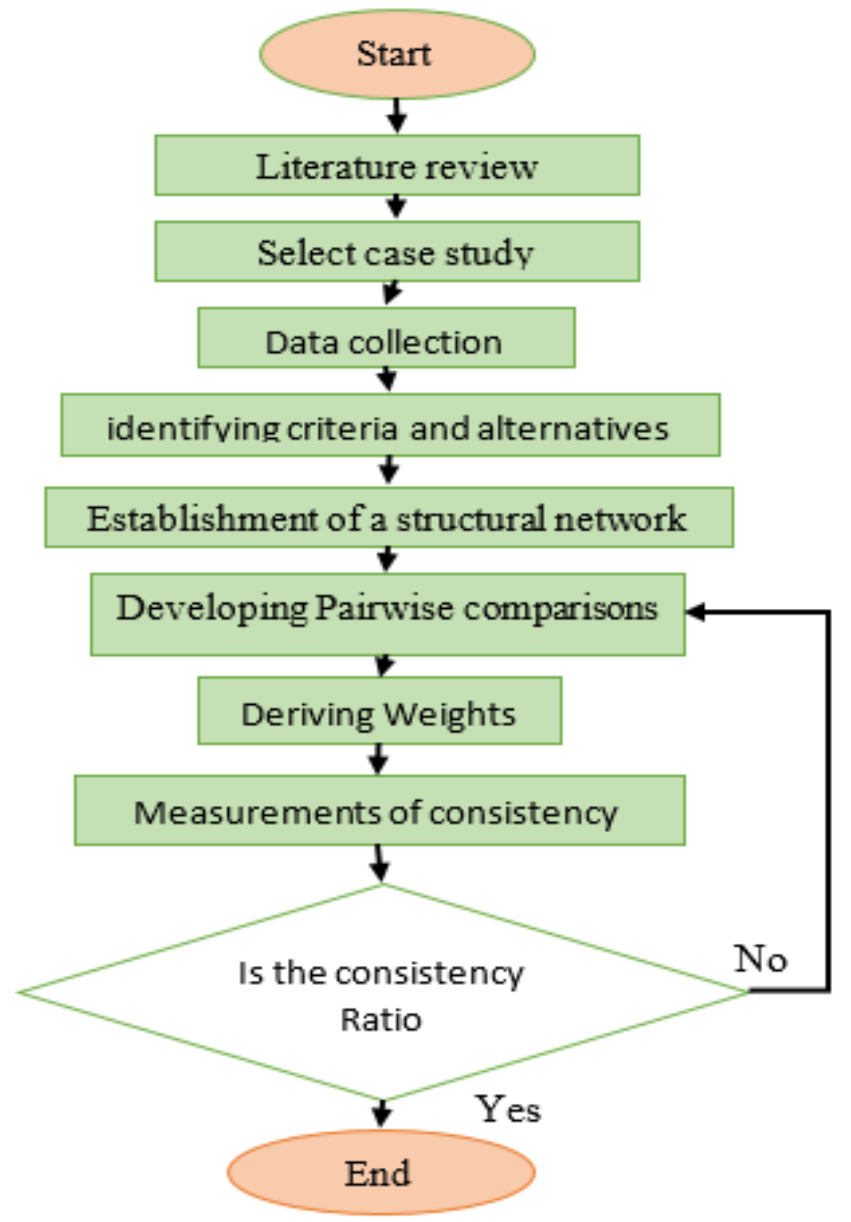

Figure 1. Framework for research methodology 
Table 1: Criteria and alternatives

\begin{tabular}{|l|c|}
\hline Criteria & Alternatives \\
\hline Percent of completion & BOT \\
Project nature and type & BOOT \\
Allocation of risk and sharing & BOO \\
economic framework has developed & DBFO \\
Environmental conservation & \\
\hline
\end{tabular}

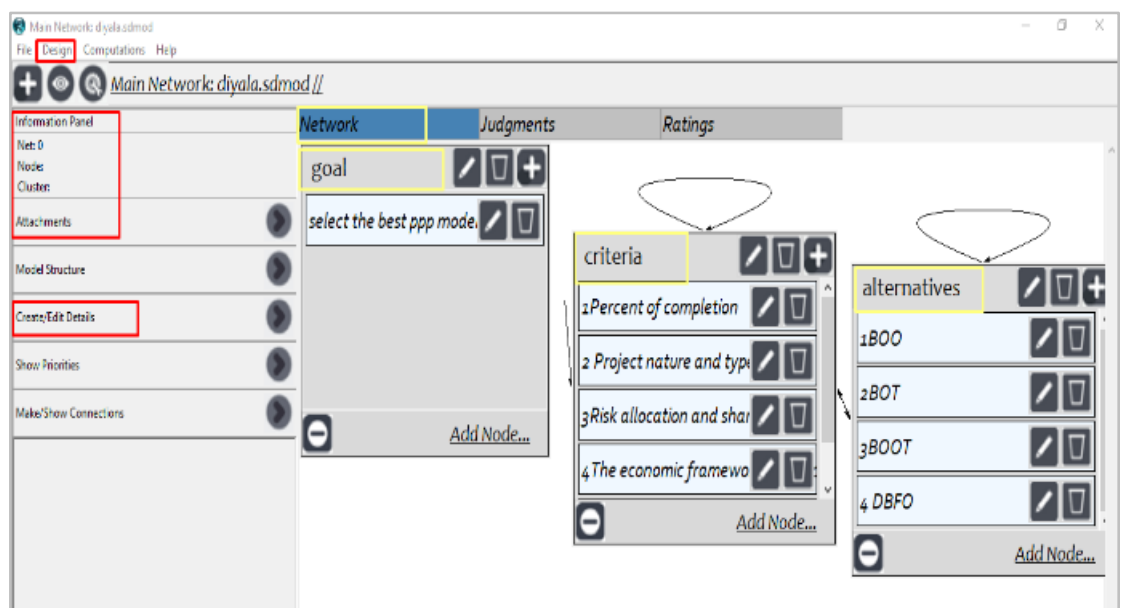

Figure 1. Structure of the ANP in the super decision's software

\section{Case study}

To achieve the research goal, the Al- Razi complex project in Diyala was chosen as a case study. This case consists of various buildings, each of which differs in dimensions and type from the others. Work began on the project in 2010, and construction was suspended in 2013 due to the country's economic crisis and the security situation at the time.

\section{Results and discussion}

5.1 Respondents' general information

The respondents' general demographics revealed that the majority of respondents had a bachelor's degree $(70 \%)$, as illustrated in Figure 3. The majority are civil engineers with a percentage of $(60 \%)$, as shown in Figure 4. Figure 5 shows that the majority of respondents less than 5 years $(33 \%)$ of experience, which contributes significantly to the survey.

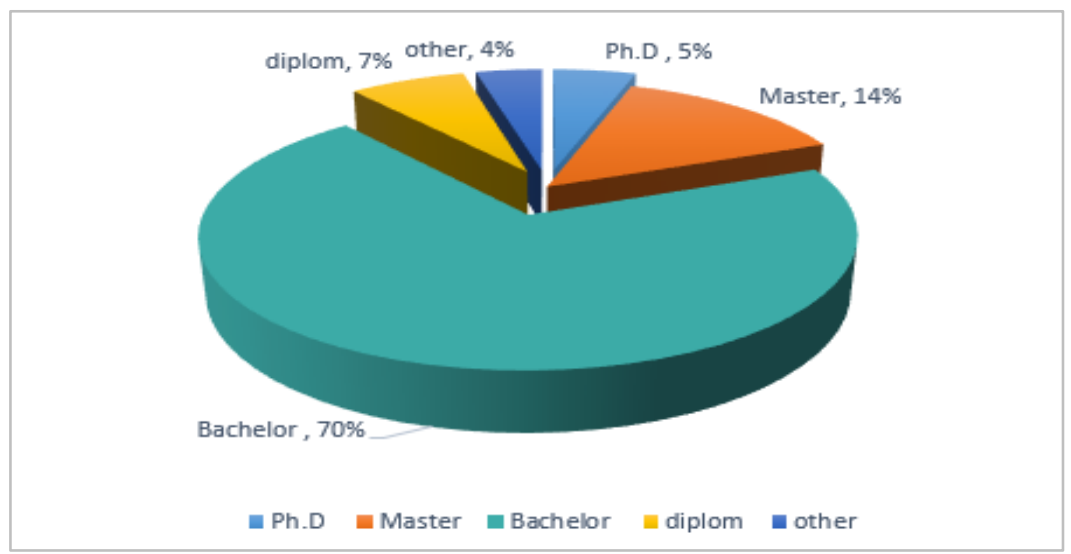

Figure 3. Level of education of the respondents 


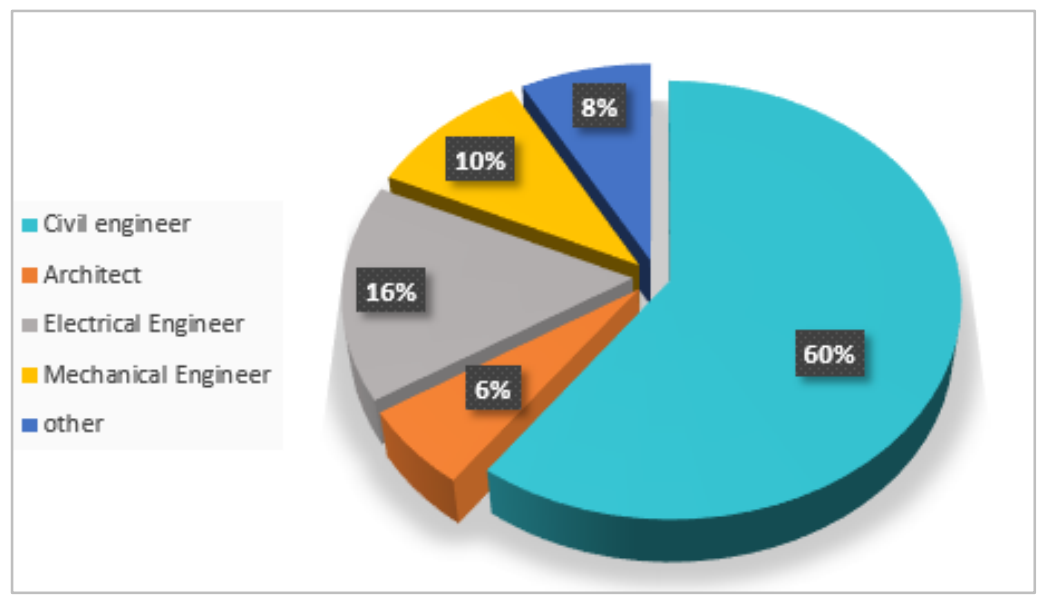

Figure 4. Respondent specialization

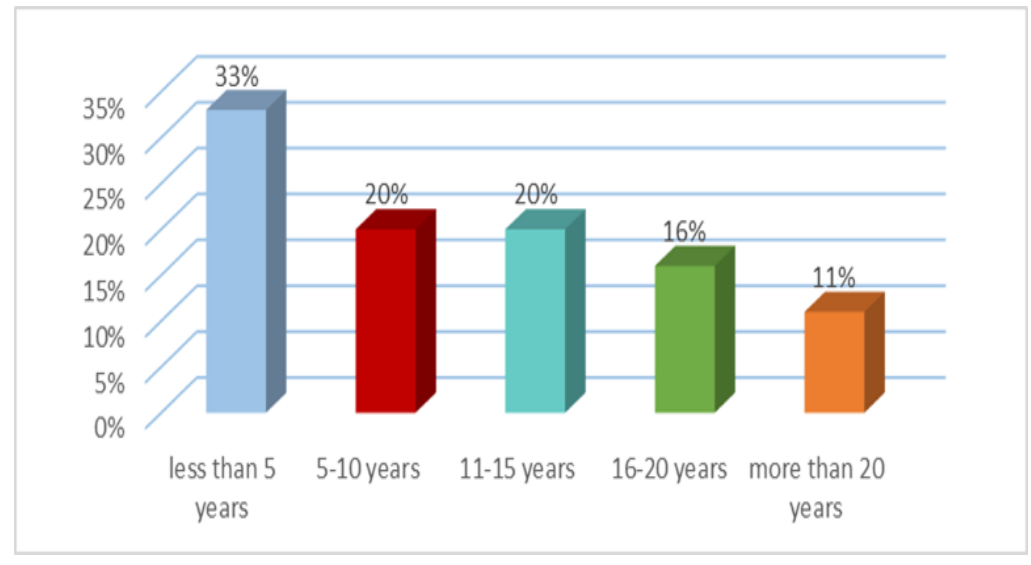

Figure 5. Years of experience

5.2 Using SPSS to test the reliability of a research tool

In this study, questionnaire reliability was measured by SPSS, Cronbach's alpha $(\mathrm{C} \alpha)$ test was used. The results are 0.85 , which is within the acceptable range, indicating that the questionnaire is reliable.

\subsection{Pairwise comparisons of criteria and alternatives}

The researcher used the super decision software for determining the weights of criteria and alternatives. After the design of the network model, the pair-wise comparison of the decision between criteria and alternatives for the optimal choice of PPP contracts in construction projects. Figure 6 shows the pairwise comparison questionnaire for criteria and Figure 7 shown alternatives, from applying ANP software.

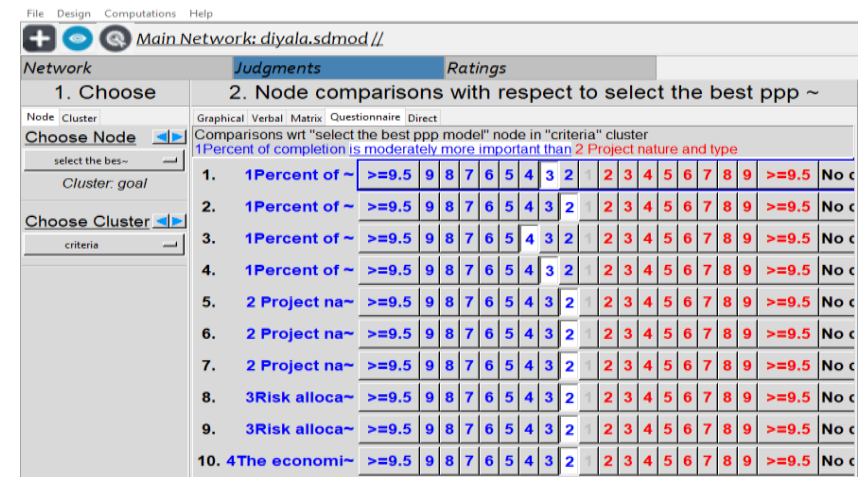

Figure 6. Pairwise comparison between criteria with respect to the goal 


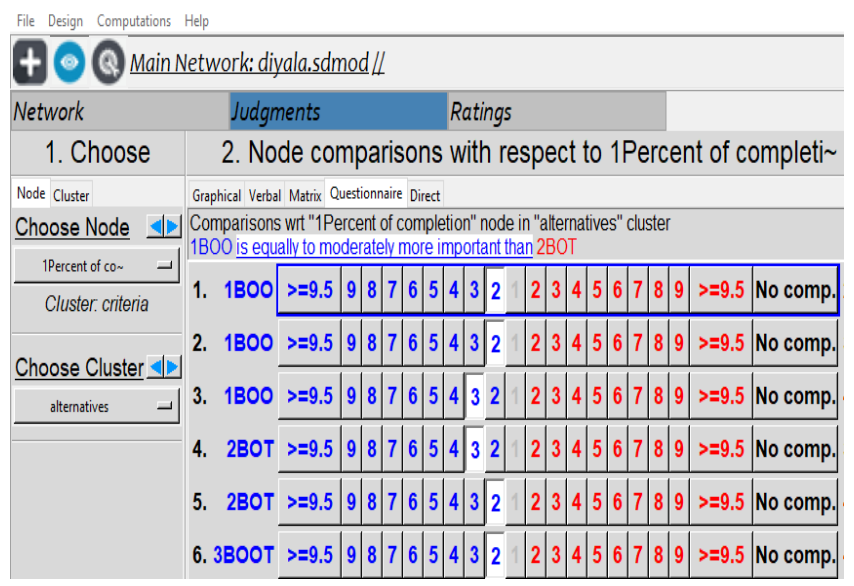

Figure 7. Pairwise comparison by super decisions software for the alternatives

\subsection{Specify the weights of criteria}

The weights of the different criteria were extracted from a pairwise comparison of the relative importance of all evaluation criteria using the Super Decisions software. The priorities (weights) of criteria with respect to the goal are shown in figure 8 . The result shows that the main criteria for the selection of PPP contracts in construction projects are Percent of completion, a Project nature and type, with the highest weight equal to 0.455 and 0.204 respectively. This is an indicator of the importance of determining the Percent of completion and nature of the project to choose the type of contract as well as the importance of the need to classify projects by types of matching contracts, risk allocation and sharing, environmental conservation, and the economic framework has developed and environmental conservation with a weight of $0.113,0.124$ and 0.111 respectively, ensuring good performance, achieving specifications, and providing effective contractors to implement the project. The results are consistent with the consistency ratio (CR) of 8.8\%. According to Saaty (2008), the internal consistency ratio (CR) in ANP should be less than $10 \%$; thus, the data collected are consistent and reliable.

\begin{tabular}{|c|c|c|c|c|}
\hline \multicolumn{5}{|c|}{ (8) Main Network: ANPd.sdmod: Priorities } \\
\hline \multicolumn{5}{|c|}{ Here are the priorities. } \\
\hline Icon & Name & Normalized by Cluste & Limiting & $\bar{\wedge}$ \\
\hline Nolcon & 1 Percent of completion & 0.44584 & $\longdiv { 0 . 2 1 6 2 3 7 }$ & \\
\hline Nolcon & 2 Project nature and type & 0.20445 & $\longdiv { 0 . 0 9 9 1 5 9 }$ & \\
\hline Nolcon & $\begin{array}{l}\text { 3Risk allocation and } \\
\text { sharing }\end{array}$ & 0.11367 & 0.055131 & \\
\hline Nolcon & $\begin{array}{l}\text { 4he economic framework } \\
\text { developed }\end{array}$ & 0.11185 & 0.054247 & \\
\hline No Icon & $\begin{array}{l}\text { 5Environmental } \\
\text { conservation }\end{array}$ & 0.12419 & 0.060232 & \\
\hline Nolcon & select the best ppp model & 0.00000 & 0.000000 & $\checkmark$ \\
\hline Okay $\mid \mathrm{C}$ & Copy Values & & & \\
\hline
\end{tabular}

Figure 7. Pairwise comparison by super decisions software for the alternatives

\subsection{Specify the weights of alternatives}

Priorities (weights) of alternatives with respect to the criteria; shows in figure 9. The result shows that the best contract type that meets all criteria the $\mathrm{BOO}$ contract with a weight equal to 0.533 , indicating that best for achieving completion of the project and also the private sector may have a better knowledge of this contract. The BOT and BOOT contract second and third rank with a weight equal to 0.194 and 0.146 respectively and the last contract is DBFO rank four with a weight equal to 0.127 . 


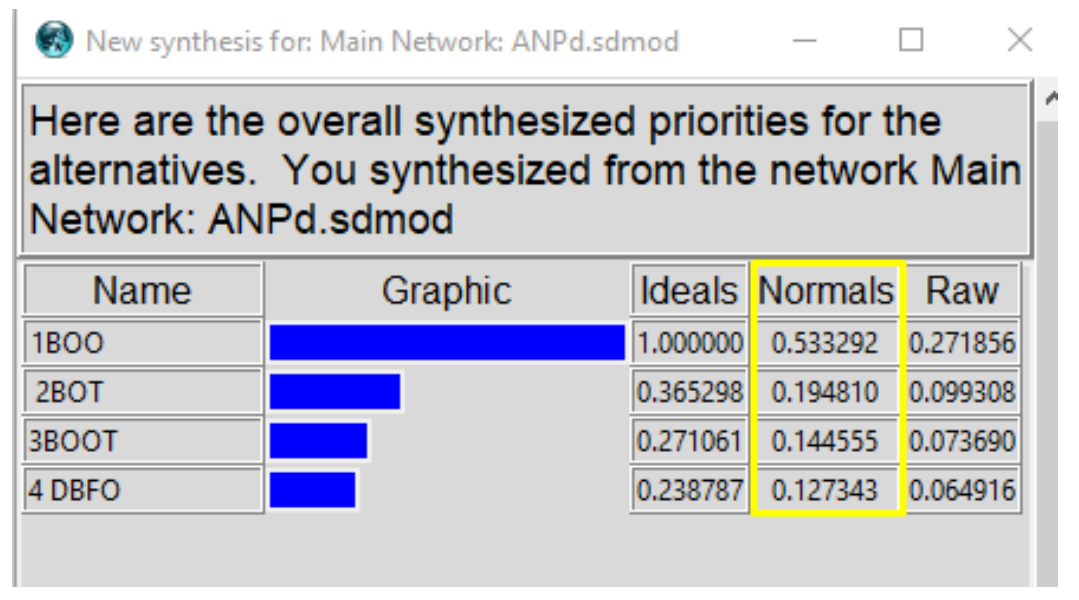

Figure 9. Synthesizing the relative weights of alternatives

\subsection{Sensitivity analysis}

Sensitivity analysis was carried out to study the effect of the different criteria on the determination of the appropriate type of contract. This analysis was measured in two respects. In the first aspect, the relative importance of one criterion has been changed from the recorded value as the basis of the survey to the sole criterion for determining the appropriate type of contract (by increasing its weight to be the maximum, equal to 9 with respect to the other criteria)., The second side reveals the type of contract that is appropriate if a criterion is not considered (by decreasing its weight to be the minimum equaled 0.111 with respect to other criteria), maximize the weight of Project nature and type. Minimizing the weight of risk allocation and sharing. The result, in this case, is that the BOO contract remains dominant, with differences over the other types of contracts ranking, other criteria play a role in changing the priority of the types of contracts without changing their ranking. The results of the sensitivity analysis are shown in Figure 10.

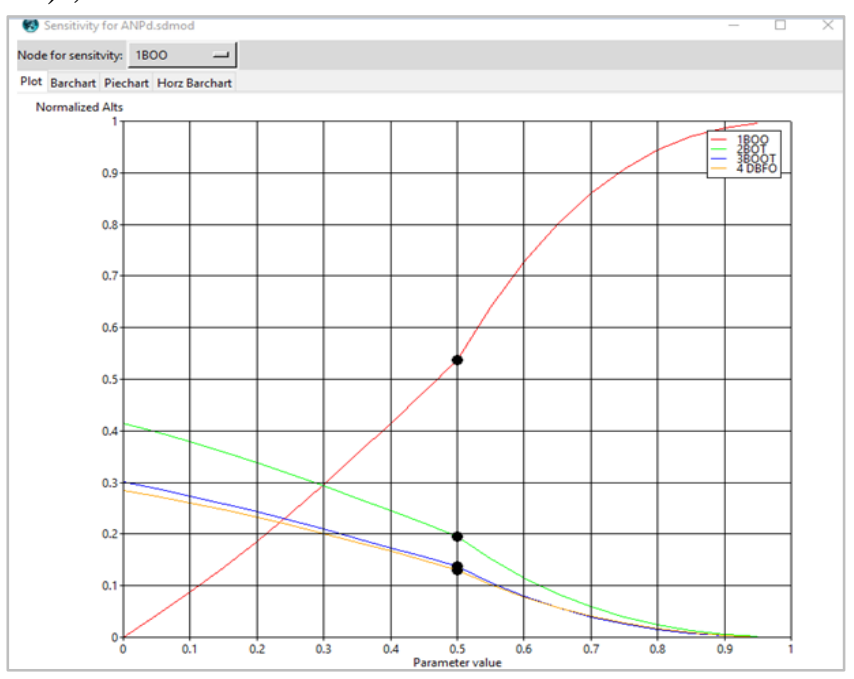

Figure 10. Result of sensitivity analysis

\section{Conclusion}

Focusing on unfinished projects is one of the major challenges facing the construction industry in developing countries like Iraq, as a result of financial crises, which have resulted in projects being stalled or abandoned in Iraq. As a result, the authors are attempting to choose the best funding model for PPP using ANP technology in order to complete the project,the authors conclude the following:

1. Using the program software ANP to evaluate the best the Public-Private 
Partnership contract in abandoned projects is an effective tool for dealing with complex decision-making where results show that the best contract type that meets all criteria the BOO contract with a weight equal to 0.533 , considered best, which improves the financing performance of the building during its lifecycle.

2. Based on ANP technology, the PPP contracts criteria weights are Percent of completion, a Project nature and type, with the highest weight equal to 0.455 and 0.204 respectively and this result indicates that this criterion is of great importance for the selection of PPP contracts in abandoned projects

3. Lack of professionalism in most management strategy, particularly with regard to the financial allocation of resources, as well as the spread of corruption and lack of transparency and justice.

4. The limitations of this research are applying ANP to choose the best financing model at the construction stage of the project. For future study using various methods and case studies to determine the best funding model in construction projects.

\section{References}

[1] Adebisi, Emmanuel Oluwatobi, Stephen Okunola Ojo, and Oluwaseyi Olalekan Alao. "Assessment of factors influencing the failure and abandonment of multi-storey building projects in Nigeria." International Journal of Building Pathology and Adaptation (2018).

[2] Ayodele, Elijah Olusegun. "Abandonment of construction projects in Nigeria: causes and effects." Journal of Emerging Trends in Economics and Management Sciences 2, no. 2 (2011): 142-145.

[3] Ayudhya, Borvorn Israngkura $\mathrm{Na}$, and Masahiko Kunishima. "Risks of Abandonment in Residential Projects Caused by Subcontractors." Procedia computer science 121 (2017): 232-237.

[4] Adil, Abdullah, Tariq Abdulmajid, and Samiaah Mahdi. "Analytical Study of the Causes of Abandoned Construction Projects." Civil Engineering Journal 5, no. 11 (2019): 2486-2494.

[5] Ihuah, Paulinus Woka, and ABIYE MIEBAKA Benebo. "An assessment of the causes and effects of abandonment of development projects on real property values in Nigeria." International Journal of Research in Applied, Natural and social sciences 2, no. 5 (2014): 25-36.

[6] Kondo, Michelle C., Danya Keene, Bernadette C. Hohl, John M. MacDonald, and Charles C. Branas. "A difference-in-differences study of the effects of a new abandoned building remediation strategy on safety." PloS one 10, no. 7 (2015): e0129582.

[7] Hussin, Abdul Aziz, and Abdelnaser Omran. "Implication of non-completion projects in Malaysia." ACTA Technica Corviniensis-Bulletin of Engineering 4, no. 4 (2011): 29.

[8] Cheung, Esther, Albert PC Chan, and Stephen Kajewski. "Enhancing value for money in public private partnership projects." Journal of Financial Management of Property and Construction (2009).

[9] Ministry of Planning, Baghdad, Iraq Budget execution report, (2019).

[10]Zimmermann, J., \& Aljuboori, O. (2013). The Challenges of Governing Public Private Partnership in Iraq Infrastructure Projects. In Creative Construction Conference, Budapest, Hungary.

[11] Mohammed, Ali Omar, and Timuçin Harputlugil. "Conceptual Framework for a Decision-Making Model Based on the Analytic Hierarchy Process (AHP) To Select the Best Public Private Partnership (PPP) Model for Airports." Nzaar Scientific Committee (2017): 99.

[12] Noorzai, Esmatullah, Kobra Gharouni Jafari, Mahmood Golabchi, and Sahar Hamedi. "Selecting an appropriate finance method of public-private partnership for railway projects in Iran through AHP method." International Journal of Structural and Civil Engineering Research 5, no. 1 (2016): 74-79.

[13] Turan, F. K., Scala, N. M., Sacre, M. B., \& Needy, K. L. (2009). An Analytic Network Process (ANP) approach to the project portfolio management for Organizational Sustainability. In Proceedings of the Industrial Engineering Research Conference. Institute of Industrial Engineers.

[14] Azis IJ. Analytic network process with feedback influence: a new approach to impact study. InPaper for Seminar Organized by Department of Urban and Regional Planning, University of Illinois at Urbana-Campaign 2003 Nov 18.

[15] Ekawati, Ratna, Dyah Lintang Trenggonowati, and Viki Dwi Aditya. "Penilaian Performa Supplier Menggunakan Pendekatan Analytic Network Process (ANP)." Journal Industrial Servicess 3, no. 2 (2018).

[16] Anopchenko, Tatiana, Olga Gorbaneva, Elena Lazareva, Anton Murzin, and Gennady Ougolnitsky. "Modeling Public_-Private Partnerships in Innovative Economy: A Regional Aspect." Sustainability 11, no. 20 (2019): 5588.

[17]Rezouki, Sedqi Esmaeel, and Jinan Kata'A. Hassan. "An evaluation of barriers obstructing the applicability of Public Private Partnership (PPP) in 
infrastructure development." Civil Engineering Journal 5, no. 12 (2019): 2643-2664.

[18] Cheng, Zhe, Huanming Wang, Wei Xiong, Dajian Zhu, and Le Cheng. "Public-private partnership as a driver of sustainable development: toward a conceptual framework of sustainability-oriented PPP." Environment, Development and Sustainability 23, no. 1 (2021): 1043-1063.

[19] Al-Shadeedi, Aqeel Salahuddin Mahdi, Angham EA Al-Saffar, and Azhar Hussein Salih. "Main Reasons for Using of PPP Contracts in Health Sector: An Analytical Study." Civil Engineering Journal 5, no. 9 (2019): 1983-1996.

[20] Motlag, Mohammed Hussain, and Redvan Ghasemlounia. "Method of Partnership with the Private Sector in Iraq." Available at SSRN 3822123 (2021). 